\title{
Epidemiologic and Clinical Features of Lassa Fever Outbreak in Nigeria, January 1-May 6, 2018
}

\author{
Elsie A. Ilori, ${ }^{1}$ Yuki Furuse, ${ }^{1}$ Oladipupo B. Ipadeola, ${ }^{1}$ Chioma C. Dan-Nwafor, ${ }^{1}$ \\ Anwar Abubakar, Oboma E. Womi-Eteng, Ephraim Ogbaini-Emovon, Sylvanus Okogbenin, \\ Uche Unigwe, Emeka Ogah, Olufemi Ayodeji, Chukwuyem Abejegah, Ahmed A. Liasu, \\ Emmanuel O. Musa, Solomon F. Woldetsadik, Clement L.P. Lasuba, \\ Wondimagegnehu Alemu, Chikwe Ihekweazu, Nigeria Lassa Fever National Response Team²
}

\begin{abstract}
Medscape ACTIVITY
In support of improving patient care, this activity has been planned and implemented by Medscape, LLC and Emerging Infectious Diseases. Medscape, LLC is jointly accredited by the Accreditation Council for Continuing Medical Education (ACCME), the Accreditation Council for Pharmacy Education (ACPE), and the American Nurses Credentialing Center (ANCC), to provide continuing education for the healthcare team.

Medscape, LLC designates this Journal-based CME activity for a maximum of 1.00 AMA PRA Category 1 Credit(s) $^{\mathrm{TM}}$. Physicians should claim only the credit commensurate with the extent of their participation in the activity.

Successful completion of this CME activity, which includes participation in the evaluation component, enables the participant to earn up to $1.0 \mathrm{MOC}$ points in the American Board of Internal Medicine's (ABIM) Maintenance of Certification (MOC) program. Participants will earn MOC points equivalent to the amount of CME credits claimed for the activity. It is the CME activity provider's responsibility to submit participant completion information to ACCME for the purpose of granting ABIM MOC credit.

All other clinicians completing this activity will be issued a certificate of participation. To participate in this journal CME activity: (1) review the learning objectives and author disclosures; (2) study the education content; (3) take the post-test with a $75 \%$ minimum passing score and complete the evaluation at http://www.medscape.org/journal/eid; and (4) view/print certificate. For CME questions, see page 1260 .
\end{abstract}

Release date: May 17, 2019; Expiration date: May 17, 2020

Learning Objectives

Upon completion of this activity, participants will be able to:

- Describe epidemiological characteristics of the Lassa fever (LF) outbreak between January 1, 2018, and May 6, 2018, in Nigeria

- Determine clinical characteristics and mortality in the LF outbreak between January 1, 2018, and May 6, 2018, in Nigeria

- Explain factors associated with mortality in the LF outbreak between January 1, 2018, and May 6, 2018, in Nigeria.

CME Editor

Jude Rutledge, BA, Technical Writer/Editor, Emerging Infectious Diseases. Disclosure: Jude Rutledge has disclosed no relevant financial relationships.

CME Author

Laurie Barclay, MD, freelance writer and reviewer, Medscape, LLC. Disclosure: Laurie Barclay, MD, has disclosed no relevant financial relationships.

\section{Authors}

Disclosures: Elsie Ilori, MSc; Yuki Furuse, MD, PhD; Oladipupo Ipadeola, MPH; Chioma Dan-Nwafor, MPH; Michael Onoja Amedu, MSC; Akanimo Iniobong, BSc; Ayodele Adeyemo, BTech; Anwar Abubakar, BS; Saliu Oladele, MBA; Esther Namukose Muwanguzi, DVM, MPH; Tanyth de Gooyer, PhD, MPhil (Appl.Epi), MPH; Oboma Eteng Womi-Eteng, MSc; Samuel Kitgakka Mutbam, MD, MPH; Emmanuel Onuche Musa, MD, MPH; Solomon F. Woldetsadik, MD; Lugala Peter Clement, MBBS, MPH; Wondimagegnehu Alemu, MD, MPH\&TM, FAIPH; and Chikwe Ihekweazu, MBBS, MPH, FFPH, have disclosed no relevant financial relationships.

Author affiliations: Nigeria Centre for Disease Control, Abuja, Nigeria (E.A. Ilori, O.B. Ipadeola, C.C. Dan-Nwafor, A. Abubakar, O.E. Womi-Eteng, C. Ihekweazu); Kyoto University, Kyoto, Japan (Y. Furuse); World Health Organization, Abuja (Y. Furuse, E.O. Musa, S.F. Woldetsadik, C.L.P. Lasuba, W. Alemu); US Centers for Disease Control and Prevention, Abuja (O.B. Ipadeola); African Field Epidemiology Network, Abuja (C.C. Dan-Nwafor); Irrua Specialist Teaching Hospital, Irrua, Nigeria (E. Ogbaini-Emovon,
S. Okogbenin); Federal Teaching Hospital, Abakaliki, Nigeria (U. Unigwe, E. Ogah); Federal Medical Centre, Owo, Nigeria (O. Ayodeji, C. Abejegah, A.A. Liasu)

DOI: https://doi.org/10.3201/eid2506.181035

${ }^{1}$ These first authors contributed equally to this article. ${ }^{2}$ Other members of the Nigeria Lassa Fever National Response Team are listed at the end of this article. 
Lassa fever (LF) is endemic to Nigeria, where the disease causes substantial rates of illness and death. In this article, we report an analysis of the epidemiologic and clinical aspects of the LF outbreak that occurred in Nigeria during January 1-May 6, 2018. A total of 1,893 cases were reported; 423 were laboratory-confirmed cases, among which 106 deaths were recorded (case-fatality rate $25.1 \%$ ). Among all confirmed cases, 37 occurred in healthcare workers. The secondary attack rate among 5,001 contacts was $0.56 \%$. Most $(80.6 \%)$ confirmed cases were reported from 3 states (Edo, Ondo, and Ebonyi). Fatal outcomes were significantly associated with being elderly; no administration of ribavirin; and the presence of a cough, hemorrhaging, and unconsciousness. The findings in this study should lead to further LF research and provide guidance to those preparing to respond to future outbreaks.

$\mathrm{L}$ assa fever (LF) is a febrile infectious disease caused by Lassa virus. The disease was first described in Nigeria in 1969 (1). Rodents, particularly Mastomys natalensis, are considered the natural hosts of the virus (2). The disease is mainly spread to humans through contamination with the urine or feces of infected rats $(3,4)$. Human-to-human transmission can occur through contact with the body fluids of infected persons; therefore, healthcare workers (HCWs) are at high risk for infection when the standard precautions for infection prevention and control are inadequate $(5,6)$. The incubation period of the disease is 3-21 days. The clinical manifestation of the disease is nonspecific and includes fever, fatigue, hemorrhaging, gastrointestinal symptoms (vomiting, diarrhea, and stomachache), respiratory symptoms (cough, chest pain, and dyspnea), and neurologic symptoms (disorientation, seizures, and unconsciousness) (3). The observed case-fatality rate (CFR) among patients hospitalized for severe LF is $15 \%-50 \%(7,8)$. However, $\approx 80 \%$ of infections are considered to cause mild or no symptoms in humans and are undiagnosed (8).

In Nigeria, laboratory-confirmed LF patients are treated in isolation units, according to national guidelines, to prevent community and nosocomial human-to-human infections (9). The country has 3 main LF treatment centers: the Irrua Specialist Teaching Hospital (Edo State), the Federal Medical Centre Owo (Ondo State), and the Federal Teaching Hospital Abakaliki (Ebonyi State) (10). Isolation units are also located in tertiary-care centers in other states. Ribavirin has been shown to reduce the CFR for LF (11); Nigeria national guidelines recommend that parenteral ribavirin be administered over a 10-day period for patients with confirmed LF (9).

Lassa fever is endemic to the West Africa countries of Benin, Ghana, Guinea, Liberia, Mali, Sierra Leone, and Nigeria (7); an estimated 300,000 LF cases occur each year in this region, resulting in $\approx 5,000$ deaths $(8)$. The annual peak of LF cases in Nigeria is observed in the dry season
(December-April), and the number decreases around May (3). The increased likelihood of humans encountering Mastomys rodents and their excreta inside houses during the dry season (when these animals are seeking food) is thought to play a role in the seasonality of disease incidence (12). Transmission risk might be exacerbated by enhanced survival of the virus at decreased relative humidity (13).

During 2014-2016, around 100 laboratory-confirmed LF cases were reported annually in Nigeria $(14,15)$. From the end of 2017 through May 2018, the country experienced its largest recorded LF outbreak. On January 22, 2018, the Nigeria Centre for Disease Control (NCDC) activated its Emergency Operations Centre to coordinate the outbreak response (16). During January 1-May 6, 2018, a total of 423 laboratory-confirmed cases were reported (17). On May 10, 2018, NCDC announced the end of the emergency phase of the outbreak because the LF case count had consistently declined in the preceding 6 weeks and had dropped below levels considered to be a national emergency, based on historical trends in LF incidence (10). Here we describe the epidemiologic and clinical aspects of this LF outbreak.

\section{Methods}

\section{Ethics Considerations}

This investigation was performed as a part of the LF public health response in Nigeria in 2018. The investigation was not considered to be research on human subjects, as per the US Department of Health and Human Services' Federal Policy for the Protection of Human Subjects (18).

\section{Case Definition and Laboratory Confirmation}

A suspected case of LF was defined as illness meeting 1 of the following criteria: 1 ) $\geq 1$ signs/symptoms (e.g., malaise, fever, headache, sore throat, cough, nausea, vomiting, diarrhea, myalgia, central chest pain or retrosternal pain, and hearing loss) and a history of contact with excreta or urine of rodents; 2) $\geq 1$ signs/symptoms and a history of contact with a person with probable or confirmed LF within 21 days of symptom onset; or 3) inexplicable bleeding or hemorrhaging (9). Probable LF cases were defined as any suspected case in a patient who died without the collection of a specimen for laboratory testing (9). Confirmed LF cases were defined as any suspected case with a laboratory confirmation (positive for IgM antibody, reverse transcription PCR [RT-PCR], or virus isolation) (9).

During the study period, blood samples from patients with suspected cases were sent to 1 of 4 laboratories: the Central Research Laboratory at College of Medicine of the University of Lagos-Lagos University Teaching Hospital (Lagos State), the Federal Teaching Hospital Abakaliki (Ebonyi State), the Institute of Lassa Fever Research and Control at the Irrua Specialist Teaching Hospital (Edo 
State), or the National Reference Laboratory (Federal Capital Territory). Laboratory confirmation was performed by using RT-PCR by means of the RealStar Lassa Virus RTPCR Kit (Altona Diagnostics, https://www.altona-diagnostics.com), the LF diagnosis protocol developed by Nikisins et al. (19), or both. More than $95 \%$ of samples were tested by using both protocols to ensure greater sensitivity for the heterogeneous Lassa virus in Nigeria (20). A positive result in either or both of the protocols was regarded as positive for LF.

\section{Contact Tracing}

Persons who had contact with patients with confirmed LF were recorded and followed up daily for 21 days by Disease Surveillance and Notification Officers (DSNOs). If contacts had symptoms, blood samples were collected and tested for LF as described.

\section{Data Collection and Report}

All suspected LF cases were immediately reported to the DSNO for each Local Government Area and the State Epidemiologist for each state by using a surveillance reporting form developed for integrated disease surveillance and response in Nigeria (21). Samples were collected and tested for all suspected cases as long as the case-patient was alive (9). If the test was positive, detailed demographic (age, sex, and residential address), clinical (symptoms, outcome, and administration of ribavirin), and epidemiologic (occupation, onset date, and exposure history) information were collected by using a national case investigation form (CIF). All suspected, probable, and confirmed cases were line listed, and the information in the CIFs was submitted weekly by the state epidemiologists to NCDC. A summary of the figures was published weekly in a situation report (17); the compiled reports of the outbreak are provided in the Appendix (https://wwwnc.cdc.gov/EID/ article/25/6/18-1035-App1.pdf). The projected population figures of each state were obtained from a report based on data from the National Population Commission of Nigeria and the National Bureau of Statistics (22). Anonymized clinical and epidemiologic data of case-patients are available by request, contingent on the recipient agreeing to appropriate guidelines for their use.

\section{Statistical Analyses}

We conducted binomial logistic regression analyses to determine the age- and sex-adjusted odds ratio (aOR) among survived and deceased patients with laboratory-confirmed LF. Likewise, we used aORs to compare the presence of each symptom and the administration of ribavirin among these cases, adjusted for age and sex. We conducted the Mantel-Haenszel test to see the statistical trend of CFR through the outbreak. We conducted chi-square tests to detect the statistical difference in exposure history between HCWs and non-HCWs.

We performed statistical tests using SPSS version 24 (IBM, https://www.ibm.com). We computed 95\% CIs and $\mathrm{p}$ values to test statistical significance and adjusted $\mathrm{p}$ values by the Bonferroni correction for multiple comparisons. A p value of $<0.05$ was considered statistically significant.

\section{Results}

During the study period (January 1-May 6, 2018), a total of 1,893 suspected LF cases were reported, including 10 probable cases and 423 laboratory-confirmed cases. The laboratory-confirmed cases were reported from 20 states and the Federal Capital Territory. Most (80.6\%) of the laboratory-confirmed cases were reported from the 3 states with a dedicated LF treatment center: Edo (178 cases), Ondo (99 cases), and Ebonyi (64 cases) (Figure 1, panel A). LF incidence was highest in these 3 states (Table 1). Edo and Ondo also had the largest number of laboratory-negative suspected cases. The positive rate (i.e., the proportion of the number of laboratory-confirmed cases among all persons with suspected cases tested) was $22.5 \%(423 / 1,883)$ nationally, ranging from $3.4 \%$ (Lagos) to $70.0 \%$ (Delta). Among the 3 states with the highest number of cases, the positive rates were $16.5 \%$ (Edo), $31.6 \%$ (Ondo), and 69.6\% (Ebonyi).

CFR among the laboratory-confirmed cases was $25.1 \%(106 / 423$ [95\% CI $20.9 \%-29.2 \%])$. Among the 3 most affected states, CFR was $14.6 \%$ (Edo), $24.2 \%$ (Ondo), and 23.4\% (Ebonyi) (Table 1). Among the 423 cases, a total of 414 CIFs with detailed information, including demographic information, onset date, symptoms, exposure history, and ribavirin administration, were collected (collection rate $97.9 \%$ ). However, the data in some fields of the CIFs were incomplete. For example, the onset date was unknown in $2.4 \%(10 / 414)$ of cases, and symptom information was missing in $12.8 \%$ (53/414). An epidemic curve based on the onset date for laboratoryconfirmed cases peaked at epidemiologic week 5 in 2018 (Figure 1, panel B). No statistically significant change was observed in the national CFR throughout the outbreak ( $\mathrm{p}$ value for trend $=0.41$ ).

We analyzed the age and sex distribution of the 414 patients with laboratory-confirmed cases (Table 2). Median age was 32 years (interquartile range 20-44 years); 157 (37.9\%) were female and 257 (62.1\%) male. CFR was lowest in children $\leq 10$ years of age $(11.1 \%)$ and highest in adults $\geq 61$ years of age (38.2\%); the aOR of fatal outcomes in the elderly group was 4.9 (95\% CI 1.5-15.6) compared with children $\leq 10$ years of age. Adults $41-60$ years of age also had statistically higher CFRs compared with children $\leq 10$ years of age (Table 2). CFR was higher for male patients (26.6\%) than female patients $(21.8 \%)$ but was not significantly different; 


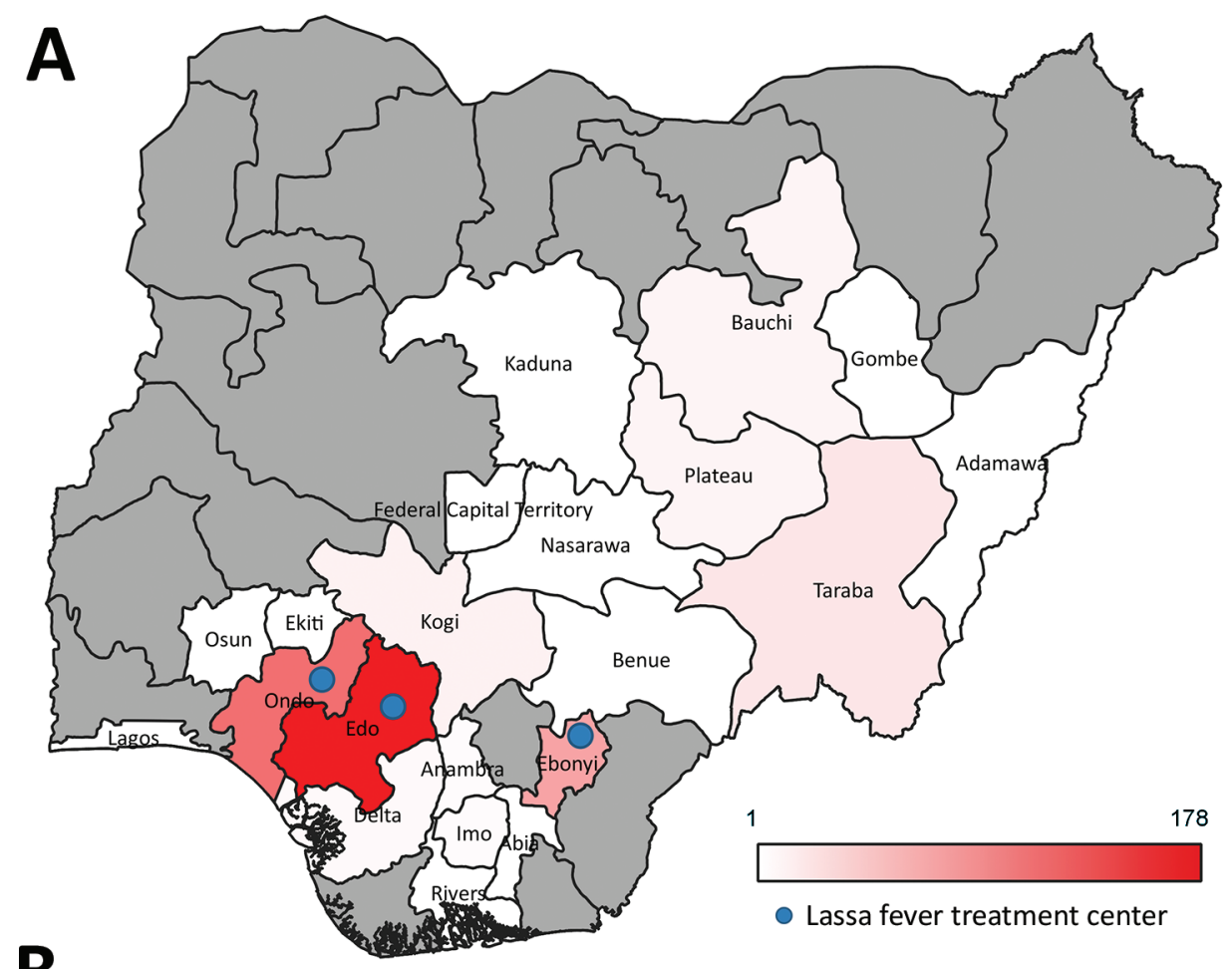

Figure 1. Geographic and temporal distribution of laboratory-confirmed Lassa fever cases, Nigeria, January 1-May 6, 2018. A) Geographic distribution of laboratoryconfirmed cases by state. Gray shading indicates states reporting no laboratoryconfirmed cases. Locations of Lassa fever treatment centers are indicated. B) Epidemic curve of laboratory-confirmed Lassa fever cases. Epidemiologic week numbers are based on the date of symptom onset.

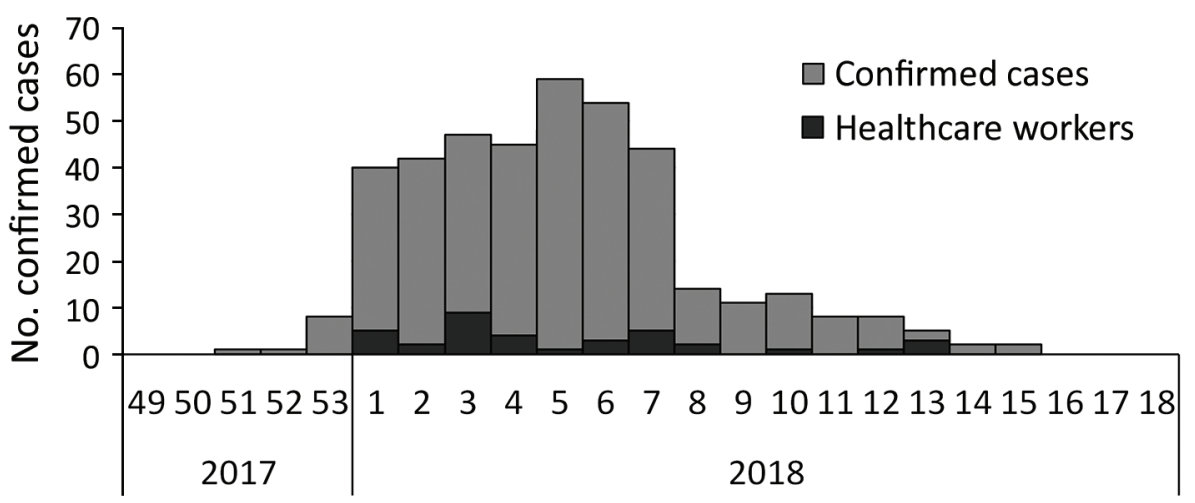

Epidemiologic week

the aOR of fatal outcomes in male patients compared with female patients was 1.3 (95\% CI 0.81-2.1).

The most common signs and symptoms among patients with laboratory-confirmed LF were fever $(96.4 \%, 348 / 361)$, headache $(58.7 \%, 210 / 358)$, vomiting $(49.4 \%, 177 / 358)$, fatigue $(43.3 \%, 155 / 358)$, and abdominal pain $(40.2 \%$, 144/358) (Table 3). Hemorrhaging was observed in $17.0 \%$ $(61 / 358)$ of these patients. Cough $(p=0.0050)$, hemorrhaging $(p<0.001)$, and unconsciousness $(p=0.0018)$ were significantly more prevalent in fatal than nonfatal cases.

During the 3 weeks before symptom onset, $17.7 \%$ (62/350) of case-patients reported contact with patients who had known suspected or confirmed LF, 17.0\% (56/330) reported contact with rodents or their urine or feces, and $2.9 \%(9 / 315)$ reported attendance at a burial ceremony
(Figure 2, panel A). During the study period, 5,012 persons were determined to have had contact with confirmed casepatients; follow-up was conducted for 5,001 of them. During the 21-day follow-up period, 81 contacts experienced onset of symptoms, and 28 were found to have laboratoryconfirmed LF. The positive rate among symptomatic contacts was $34.6 \%(28 / 81)$, and the secondary attack rate was $0.56 \%(28 / 5,001 ; 95 \%$ CI $0.35 \%-0.77 \%)$.

During the study period, $37 \mathrm{HCWs}$ were infected, resulting in 8 deaths (CFR 21.6\%). The incidence of HCW infections was distributed throughout the outbreak period (Figure 1, panel B). A significantly high proportion of HCWs $(55.9 \%, 19 / 34)$ reported contact with patients with known suspected or confirmed LF compared with nonHCWs $(\mathrm{p}<0.001)$ (Figure 2, panel A). 
Table 1. Number and incidence of Lassa fever cases, by state or territory, Nigeria, January 1-May 6, 2018

\begin{tabular}{|c|c|c|c|c|c|c|c|}
\hline State or territory & $\begin{array}{c}\text { Population, } \\
\times 1,000^{*}\end{array}$ & $\begin{array}{l}\text { No. confirmed } \\
\text { cases (deaths) }\end{array}$ & $\begin{array}{c}\text { Case-fatality } \\
\text { rate, } \%\end{array}$ & $\begin{array}{c}\text { No. confirmed } \\
\text { cases } / 100,000 \\
\text { population }\end{array}$ & $\begin{array}{c}\text { No. laboratory- } \\
\text { negative } \\
\text { suspected cases }\end{array}$ & $\begin{array}{c}\text { No. } \\
\text { probable } \\
\text { cases }\end{array}$ & $\begin{array}{l}\text { Positive } \\
\text { rate, } \%\end{array}$ \\
\hline Abia & 3,727 & $1(1)$ & 100.0 & 0.027 & 11 & 1 & 8.3 \\
\hline Adamawa & 4,248 & $1(1)$ & 100.0 & 0.024 & 2 & 1 & 33.3 \\
\hline Anambra & 5,528 & $4(2)$ & 50.0 & 0.072 & 3 & 0 & 57.1 \\
\hline Bauchi & 6,537 & $10(5)$ & 50.0 & 0.153 & 50 & 0 & 16.7 \\
\hline Benue & 5,742 & $1(1)$ & 100.0 & 0.017 & 6 & 1 & 14.3 \\
\hline Delta & 5,663 & $7(3)$ & 42.9 & 0.124 & 3 & 0 & 70.0 \\
\hline Ebonyi & 2,880 & $64(15)$ & 23.4 & 2.222 & 28 & 4 & 69.6 \\
\hline Edo & 4,236 & $178(26)$ & 14.6 & 4.202 & 901 & 0 & 16.5 \\
\hline Ekiti & 3,271 & $2(1)$ & 50.0 & 0.061 & 10 & 0 & 16.7 \\
\hline Federal Capital Territory & 3,564 & $3(2)$ & 66.7 & 0.084 & 38 & 0 & 7.3 \\
\hline Gombe & 3,257 & $2(2)$ & 100.0 & 0.061 & 13 & 0 & 13.3 \\
\hline Imo & 5,409 & $4(1)$ & 25.0 & 0.074 & 11 & 0 & 26.7 \\
\hline Kaduna & 8,252 & $1(1)$ & 100.0 & 0.012 & 4 & 0 & 20.0 \\
\hline Kogi & 4,474 & $11(4)$ & 36.4 & 0.246 & 15 & 2 & 42.3 \\
\hline Lagos & 12,551 & $1(1)^{\prime}$ & 100.0 & 0.008 & 28 & 0 & 3.4 \\
\hline Nasarawa & 2,523 & $3(2)$ & 66.7 & 0.119 & 34 & 0 & 8.1 \\
\hline Ondo & 4,672 & $99(24)$ & 24.2 & 2.119 & 214 & 1 & 31.6 \\
\hline Osun & 4,706 & $2(1)$ & 50.0 & 0.043 & 2 & 0 & 50.0 \\
\hline Plateau & 4,200 & $9(7)$ & 77.8 & 0.214 & 39 & 0 & 18.8 \\
\hline Rivers & 7,304 & $1(1)$ & 100.0 & 0.014 & 7 & 0 & 12.5 \\
\hline Taraba & 3,067 & $19(5)$ & 26.3 & 0.620 & 41 & 0 & 31.7 \\
\hline Total & 193,393 & $423(106)$ & 25.1 & 0.219 & 1.460 & 10 & 22.5 \\
\hline
\end{tabular}

Ribavirin was administered to $94.1 \%(334 / 355)$ of the patients with laboratory-confirmed cases. CFR for patients who received ribavirin was $20.7 \%(69 / 334)$, compared with $71.4 \%$ $(15 / 21)$ for patients who did not receive ribavirin (Figure 2, panel B). We also analyzed the subset of patients who survived $\geq 7$ days after symptom onset to account for the possible effect of the difference in clinical conditions. We further divided the patients who received ribavirin into 2 groups: patients who received the drug within 7 days after symptom onset and patients who received the drug after that point. Among case-patients who survived $\geq 7$ days, CFR was significantly higher for patients who did not receive any ribavirin $(66.7 \%, 12 / 18)$ compared with patients who received the drug $(\mathrm{p}<0.01)$, whether receipt of the drug occurred within 7 days of symptom onset or $>7$ days after onset (Figure 2, panel C). CFR was lower among patients who received the drug within 7 days of symptom onset $(12.5 \%, 15 / 120)$ compared with patients who received the drug after that point $(20.1 \%, 38 / 189)$, although this difference was not significant $(p=0.095)$. Because this reduction in CFR might have been attributable to not only ribavirin but also the other supportive treatments provided, the time between symptom onset date and the patient's arrival at a health facility was included in addition to age and administration of ribavirin as a covariable in the binomial logistic regression analysis for fatal outcomes. Although absence of ribavirin administration $(p<0.001)$ and advanced age $(p=0.025)$ remained significant factors in fatal outcomes, delay in visiting health facility did $\operatorname{not}(\mathrm{p}=0.19)$.

\section{Discussion}

We describe the epidemiologic and clinical features of the LF outbreak in Nigeria during January 1-May 6, 2018. A total of 423 laboratory-confirmed cases were reported during the study period. Most of the laboratory-confirmed

\begin{tabular}{|c|c|c|c|c|c|c|}
\hline Characteristic & $\begin{array}{c}\text { No. girls and } \\
\text { women (deaths) }\end{array}$ & $\begin{array}{l}\text { No. boys and } \\
\text { men (deaths) }\end{array}$ & $\begin{array}{l}\text { Total no. } \\
\text { (deaths) }\end{array}$ & $\begin{array}{c}\text { Case-fatality } \\
\text { rate, } \%\end{array}$ & aOR $(95 \% \mathrm{Cl})$ & $p$ value \\
\hline \multicolumn{7}{|l|}{ Age group, y } \\
\hline $0-10$ & $19(3)$ & $26(2)$ & $45(5)$ & 11.1 & Reference & \\
\hline $11-20$ & $24(4)$ & 42 (10) & 66 (14) & 21.2 & $2.1(0.71-6.4)$ & 0.18 \\
\hline $21-30$ & $38(5)$ & 52 (13) & 90 (18) & 20.5 & $2.1(0.71-6.0)$ & 0.18 \\
\hline $31-40$ & $30(7)$ & 60 (16) & $90(23)$ & 25.6 & $2.7(0.95-7.6)$ & 0.063 \\
\hline $41-50$ & $23(5)$ & 39 (15) & $62(20)$ & 32.3 & $3.8(1.3-11.0)$ & 0.015 \\
\hline $51-60$ & $10(4)$ & $15(4)$ & $25(8)$ & 32.0 & $3.8(1.1-13.2)$ & 0.039 \\
\hline$\geq 61$ & $12(5)$ & $22(8)$ & 34 (13) & 38.2 & $4.9(1.5-15.6)$ & 0.0074 \\
\hline Total & $157(34)$ & $257(68)$ & $423(106)$ & & & \\
\hline Case-fatality rate, $\%$ & 21.8 & 26.6 & & & & \\
\hline $\operatorname{aOR}(95 \% \mathrm{Cl})$ & Reference & $1.3(0.81-2.1)$ & & & & \\
\hline $\mathrm{p}$ value & 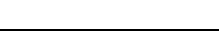 & 0.26 & & & & \\
\hline
\end{tabular}


Table 3. Prevalence of symptoms and outcomes among patients with laboratory-confirmed Lassa fever, Nigeria, January $1-$ May 6, 2018*

\begin{tabular}{|c|c|c|c|c|c|}
\hline \multirow[b]{2}{*}{ Sign/symptom } & \multicolumn{3}{|c|}{ Cases, \% (no. positive/no. with data available) } & \multirow[b]{2}{*}{ aOR $(95 \% \mathrm{Cl})$} & \multirow[b]{2}{*}{$p$ value } \\
\hline & All cases & Fatal cases & Nonfatal cases & & \\
\hline Fever & $96.4(348 / 361)$ & $97.8(87 / 89)$ & $96.3(260 / 270)$ & $1.5(0.31-7.3)$ & 1 \\
\hline Headache & $58.7(210 / 358)$ & $64.0(57 / 89)$ & $56.6(151 / 267)$ & $1.4(0.83-2.3)$ & 1 \\
\hline Vomiting & $49.4(177 / 358)$ & $56.2(50 / 89)$ & $47.6(127 / 267)$ & $1.5(0.88-2.4)$ & 1 \\
\hline Fatigue & $43.3(155 / 358)$ & $55.1(49 / 89)$ & $39.7(106 / 267)$ & $1.5(0.93-2.6)$ & 1 \\
\hline Abdominal pain & $40.2(144 / 358)$ & $49.4(44 / 89)$ & $37.1(99 / 267)$ & $1.7(1.0-2.9)$ & 0.68 \\
\hline Anorexia & $33.0(118 / 358)$ & $39.3(35 / 89)$ & $31.1(83 / 267)$ & $1.4(0.81-2.3)$ & 1 \\
\hline Cough & $30.4(109 / 358)$ & $46.1(41 / 89)$ & $25.5(68 / 267)$ & $2.6(1.6-4.4)$ & 0.0050 \\
\hline Diarrhea & $26.8(96 / 358)$ & $39.3(35 / 89)$ & $22.8(61 / 267)$ & $2.2(1.3-3.7)$ & 0.068 \\
\hline Sore throat & $22.1(79 / 358)$ & $32.6(29 / 89)$ & $18.7(50 / 267)$ & $2.0(1.1-3.5)$ & 0.33 \\
\hline Chest pain & $21.3(76 / 357)$ & $26.1(23 / 88)$ & $19.9(53 / 267)$ & $1.4(0.76-2.4)$ & 1 \\
\hline Myalgia & $18.5(66 / 357)$ & $28.4(25 / 88)$ & $15.0(40 / 267)$ & $2.1(1.2-3.8)$ & 0.28 \\
\hline Hemorrhaging & $17.0(61 / 358)$ & $37.1(33 / 89)$ & $10.1(27 / 267)$ & $5.1(2.8-9.3)$ & $<0.001$ \\
\hline Arthralgia & $16.5(59 / 357)$ & $26.1(23 / 88)$ & $13.5(36 / 267)$ & $2.3(1.2-4.3)$ & 0.17 \\
\hline Dyspnea & $14.8(53 / 357)$ & $25.0(22 / 88)$ & $11.6(31 / 267)$ & $2.6(1.4-4.9)$ & 0.061 \\
\hline Unconsciousness & $4.8(17 / 357)^{\prime}$ & $13.6(12 / 88)$ & $1.9(5 / 267)$ & $9.4(3.1-28.7)$ & 0.0018 \\
\hline Conjunctivitis & $4.5(16 / 358)$ & $6.7(6 / 89)$ & $3.7(10 / 267)$ & $2.1(0.71-6.1)$ & 1 \\
\hline Disorientation & $4.2(15 / 357)$ & $8.0(7 / 88)$ & $3.0(8 / 267)$ & $2.8(0.97-8.3)$ & 1 \\
\hline Skin rash & $3.6(13 / 358)$ & $6.7(6 / 89)$ & $2.6(7 / 267)$ & $3.0(0.97-9.6)$ & 1 \\
\hline Photophobia & $3.4(12 / 357)$ & $6.8(6 / 88)$ & $2.2(6 / 267)$ & $3.0(0.92-9.9)$ & 1 \\
\hline Hiccup & $2.5(9 / 358)$ & $6.7(6 / 89)$ & $1.1(3 / 267)$ & $6.6(1.6-28.0)$ & 0.22 \\
\hline Jaundice & $2.2(8 / 358)$ & $4.5(4 / 89)$ & $1.5(4 / 267)$ & $3.7(0.87-15.6)$ & 1 \\
\hline
\end{tabular}

cases were reported from the 3 states (Edo, Ondo, and Ebonyi) where dedicated LF treatment centers are located; disease incidence was also highest in these areas. However, the positive rate among suspected cases was not especially high for these 3 states. In addition to the high prevalence of LF in the areas, HCWs in these 3 states had a high suspicion of LF in patients with high-grade fevers, which might have led to increased testing. Conversely, suspicion of LF might be low in some areas other than these 3 states. Lack of LF expertise and diagnostic capacity in these other areas might have discouraged active detection of LF patients, leading to underreporting of the disease. Also, LF incidence and prevalence might actually be lower in some areas for epidemiologic and environmental reasons, such as low prevalence of the virus in rodents or good hygiene practices that help reduce contact between humans and rodents. To clarify different LF prevalence by areas, sensitization and strengthening of the surveillance system to detect suspected cases and obtain test samples are required, particularly in states other than Edo, Ondo, and Ebonyi. In addition, seroprevalence surveys and ecologic studies of LF in humans and rodents should give further insight on the actual burden of the disease.

We used 2 protocols for molecular diagnosis of LF to cover the heterogeneous Lassa virus in Nigeria (20), and we tested $>95 \%$ of the samples by using both protocols during the outbreak. Further study is needed to reveal sensitivity and specificity of each protocol in this country. That
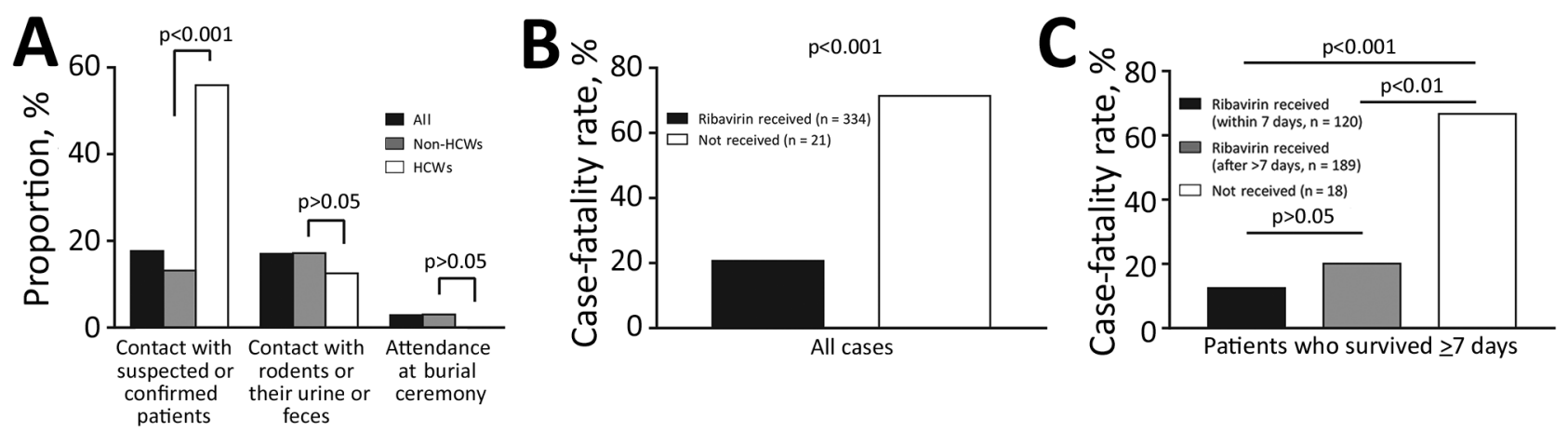

Figure 2. Exposure history and case-fatality rate among patients with laboratory-confirmed Lassa fever cases, Nigeria, January 1May 6, 2018. A) Proportion of persons reporting Lassa fever exposure risks for all case-patients, HCWs, and non-HCWs. To assess differences in exposure risks between HCWs, and non-HCWs, p values were calculated by using the $\chi^{2}$ test and adjusted by the Bonferroni correction. B) The case-fatality rate for case-patients who did or did not receive ribavirin. C) An investigation of the casefatality rate in patients who survived $\geq 7$ days after symptom onset. For panels $B$ and $C, p$ values were calculated by using binomial logistic regression analysis adjusted for age and sex and applying the Bonferroni correction. HCW, healthcare worker. 
information would also give us further insight on genetic diversity of the virus in natural hosts in the country.

Although NCDC situation reports showed the peak of the outbreak at week 7 (17), our study found that the outbreak peaked at week 5 . This difference occurred because the epidemic curve from the situation reports was based on the reporting date, whereas the epidemic curve in our study was based on symptom onset date. The difference can be explained by the time lag between symptom onset to health facility presentation and subsequent diagnosis and reporting. The median of the time lag between symptom onset to suspicion of LF was 7 days (interquartile range 4-11 days), and several additional days were required for a health facility to report through the DSNO for each Local Government Area and for the state epidemiologist in each state to report NCDC. Further strengthening of the surveillance system is required to shorten this time gap.

Girls and women accounted for a lower proportion of the laboratory-confirmed LF cases than boys and men $(37.9 \%$ vs. $62.1 \%)$. Past studies have shown no or little difference in LF incidence between male and female patients (23-25). It is unclear whether the difference in this study came because men and boys were at higher risk for infection or more susceptible to the disease than women and girls or because ascertainment of cases in women and girls was low during this outbreak.

CFR among laboratory-confirmed cases during the study period was $25.1 \%$ and did not change substantially throughout the outbreak. CFR can reach 50\% in hospitalized patients during epidemics (8), whereas the observed CFR among patients hospitalized with severe LF is $15 \%$ (7). CFR in this outbreak was especially high among elderly patients. Such difference in CFR among age groups was not observed in previous studies $(26,27)$. The large number of cases in this outbreak might have increased the statistical power to detect the difference.

Gastroenteric symptoms, including vomiting, abdominal pain, and anorexia, were frequently observed among patients with laboratory-confirmed cases ( $>30 \%)$, whereas hemorrhaging was only observed in $17.0 \%$ of case-patients (Table 3 ). This observation is consistent with previous reports $(28,29)$. Because some symptoms, such as cough, hemorrhaging, and unconsciousness, were more frequently observed for fatal cases than nonfatal cases, these symptoms might be predictors for fatal outcomes. Patients with such symptoms would require more attention to achieve better clinical outcomes.

Lassa virus is primarily transmitted to humans from rodents. The virus is also occasionally transmitted through the body fluids of infected persons (3). In this outbreak, $\approx 17 \%$ of patients reported a history of contact with rodents. A similar percentage reported contact with patients with suspected or confirmed LF. Because this information was obtained by patient interview, recall bias might have influenced the accuracy of exposure history. Although the secondary attack rate was as low as $0.56 \%$, the positive rate for LF among person with suspected cases was higher for those who had contact with confirmed case-patients than that in the general population $(34.6 \%$ vs. $22.5 \%)$. Contact tracing did not account for $34 \mathrm{LF}$ patients, although they had reported contact with other confirmed or suspected case-patients. Some case-patients might have been targeted in the contact tracing whereas others were not because they reported contact with persons with suspected (but not confirmed) cases. Strengthening and expanding contact tracing is required but posed a challenge in resource-limited settings during the outbreak. A high rate of contact with suspected or confirmed LF case-patients among HCWs suggests the possibility of nosocomial infections, although we could not rule out another source of infection, such as rodents (30). Nevertheless, good infection prevention and control practices and readily available personal protective equipment are important to protect HCWs from infection with the virus $(5,6)$.

The findings in this study support the effectiveness of ribavirin in reducing mortality rates from LF. CFR was lowest among patients who received treatment with ribavirin. Patients in severe conditions might have not received ribavirin because they died before reaching healthcare facilities where treatment was available; that is, the difference in CFRs between patients who did or did not receive ribavirin might be attributable not only to the ribavirin treatment but also to the patient's clinical condition before ribavirin administration $(6,28)$. To explore this issue further, we analyzed a subset of patients who survived $\geq 7$ days after symptom onset. The highest CFR was still observed among patients who did not receive ribavirin; CFR was lower even if provision of ribavirin was deferred to $>7$ days after symptom onset. Furthermore, the early commencement of ribavirin treatment reduced CFR compared with deferred administration of the drug, although this difference was not statistically significant. Therefore, the reduction in CFR was more likely attributable to ribavirin than to the other supportive treatments provided. These findings support $\mathrm{Ni}$ geria's national guidelines for clinical management of the disease, which advise that patient outcomes are more favorable when ribavirin treatment is commenced earlier (9).

This study has several limitations. Although we collected CIFs from 414 of the 423 patients with laboratoryconfirmed cases, the data in some fields were incomplete. Availability of CIFs for patients with suspected cases whose laboratory tests were negative would have enabled us to conduct a case-control study to better determine the risk factors for the disease; however, collection of this information for 1,460 laboratory-negative suspected cases would have been burdensome to outbreak response staff. Also, our study did not provide any insights into why the 2018 LF outbreak was larger than those in previous years. Studies using viral genomic data have suggested that the outbreak 
was not caused by ongoing human-to-human transmission from a single source but by multiple environmental sources (31). Better surveillance through increased availability of laboratory testing of suspected cases might have played a role in the larger number of laboratory-confirmed cases during this outbreak. Localized clusters, which were not investigated as part of this study, might have contributed to the inflation of case numbers in some areas.

LF is endemic in Nigeria. The LF surveillance data from Nigeria, even with their limitations, are arguably the best longitudinal data collected on LF globally. Although these data mostly relate to the 2018 outbreak, data collection has continued, and all aspects of surveillance are being continuously improved (e.g., educating $\mathrm{HCWs}$ on the case definition, increasing ease and efficiency of the transport of samples, and increasing capacity and quality of diagnosis). In this study, we described the epidemiologic and clinical features of the largest recorded LF outbreak, which had a high CFR. The investigation also revealed several risk factors for fatal outcomes and the contribution of early treatment in reduction of CFR. These findings should lead to further investigation of the disease. Our study also highlights the need for specific incidence and seroprevalence surveys to determine the actual burden of disease in Nigeria and West Africa. Although the emergency phase of this outbreak was declared over on May 10, 2018, a small number of cases in some areas continued to be reported thereafter (10). Ceaseless efforts to improve risk communication, surveillance, laboratory diagnosis, clinical management, infection prevention and control practices, logistics, and coordination could mitigate the impact of future outbreaks.

Additional members of the Nigeria Lassa Fever National Response Team: Michael Popoola, Anthony Ahumibe, Amedu M. Onoja, Akanimo Iniobong, Dike K. Ugochukwu, Favour M. Isi, Joy Musa (Nigeria Centre for Disease Control); Ayodele Adeyemo (eHealth Africa); Winifred Ukponu (University of Maryland Baltimore); Saliu Oladele, Esther N. Muwanguzi, Tanyth de Gooyer, Samuel K. Mutbam (World Health Organization); Demian U. Nwidi (Federal Teaching Hospital Abakaliki); Olumuyiwa B. Salu, Ayorinde B. James, and Sunday A. Omilabu (University of Lagos).

\section{Acknowledgments}

We thank all the staff working at the national and international organizations who fought against this outbreak, including personnel at the healthcare facilities, LF diagnostic laboratories, Nigeria Centre for Disease Control, World Health Organization, Alliance for International Medical Action, Médecins Sans Frontières, Robert Koch Institute, African Field Epidemiology Network, Public Health England, US Centers for Disease Control and Prevention, and numerous other partners. We also express our sincerest condolences to the family and friends of those who died during the outbreak.

\section{About the Author}

Ms. Ilori is an incident manager at the Nigeria Centre for Disease Control in Abuja, Nigeria. Her primary research interests include outbreak preparedness and response.

\section{References}

1. Frame JD, Baldwin JM Jr, Gocke DJ, Troup JM. Lassa fever, a new virus disease of man from West Africa. I. Clinical description and pathological findings. Am J Trop Med Hyg. 1970;19:670-6. http://dx.doi.org/10.4269/ajtmh.1970.19.670

2. Monath TP, Newhouse VF, Kemp GE, Setzer HW, Cacciapuoti A. Lassa virus isolation from Mastomys natalensis rodents during an epidemic in Sierra Leone. Science. 1974;185:263-5. http://dx.doi.org/10.1126/science.185.4147.263

3. Richmond JK, Baglole DJ. Lassa fever: epidemiology, clinical features, and social consequences. BMJ. 2003;327:1271-5. http://dx.doi.org/10.1136/bmj.327.7426.1271

4. Keenlyside RA, McCormick JB, Webb PA, Smith E, Elliott L, Johnson KM. Case-control study of Mastomys natalensis and humans in Lassa virus-infected households in Sierra Leone. Am J Trop Med Hyg. 1983;32:829-37. http://dx.doi.org/10.4269/ ajtmh.1983.32.829

5. Fisher-Hoch SP, Tomori O, Nasidi A, Perez-Oronoz GI, Fakile Y, Hutwagner L, et al. Review of cases of nosocomial Lassa fever in Nigeria: the high price of poor medical practice. BMJ. 1995;311:857-9. http://dx.doi.org/10.1136/bmj.311.7009.857

6. Ajayi NA, Nwigwe CG, Azuogu BN, Onyire BN, Nwonwu EU, Ogbonnaya LU, et al. Containing a Lassa fever epidemic in a resource-limited setting: outbreak description and lessons learned from Abakaliki, Nigeria (January-March 2012). Int J Infect Dis. 2013;17:e1011-6. http://dx.doi.org/10.1016/j.ijid.2013.05.015

7. World Health Organization. Lassa fever fact sheet [cited 2018 May 13]. http://origin.who.int/mediacentre/factsheets/fs 179

8. Centers for Disease Control and Prevention. Lassa fever [cited 2018 May 13]. http://www.cdc.gov/vhf/lassa

9. Nigeria Centre for Disease Control. Standard operating procedures for Lassa fever case management [cited 2018 May 13]. http://www. ncdc.gov.ng/themes/common/docs/protocols/30_1502277315.pdf

10. Nigeria Centre for Disease Control. Honourable Minister of Health announces end of emergency phase of Nigeria's Lassa fever outbreak [cited 2018 May 13]. http://ncdc.gov.ng/news/142/ honourable-minister-of-health-announces-end-of-emergency-phaseof-nigeria $\% 5 \mathrm{C} \% 27 \mathrm{~s}$-lassa-fever-outbreak

11. McCormick JB, King IJ, Webb PA, Scribner CL, Craven RB, Johnson KM, et al. Lassa fever. N Engl J Med. 1986;314:20-6. http://dx.doi.org/10.1056/NEJM198601023140104

12. Stephenson EH, Larson EW, Dominik JW. Effect of environmental factors on aerosol-induced Lassa virus infection. J Med Virol. 1984;14:295-303. http://dx.doi.org/10.1002/jmv.1890140402

13. Fichet-Calvet E, Lecompte E, Koivogui L, Soropogui B, Doré A, Kourouma F, et al. Fluctuation of abundance and Lassa virus prevalence in Mastomys natalensis in Guinea, West Africa. Vector Borne Zoonotic Dis. 2007;7:119-28. http://dx.doi.org/10.1089/ vbz.2006.0520

14. Nigeria Centre for Disease Control. Weekly Epidemiological Report. Weekly updates on epidemics in Nigeria: as at 16th September, 2016 [cited 2018 May 13]. http://www.ncdc.gov.ng/ reports/7/2016-september-week-37

15. Nigeria Centre for Disease Control. Weekly Epidemiological Report. Weekly updates on epidemics in Nigeria: as at 6th January, 2016 [cited 2018 May 13]. http://www.ncdc.gov.ng/ reports/23/2017-january-week-1

16. Nigeria Centre for Disease Control. Weekly Epidemiological Report. Stopping spread of Lassa fever: instituting infection 
prevention control measures in health facilities [cited 2018 May 13]. http://www.ncdc.gov.ng/reports/104/2018-januaryweek-3

17. Nigeria Centre for Disease Control. An update of Lassa fever outbreak in Nigeria for week 19 [cited 2018 May 13].

http://www.ncdc.gov.ng/themes/common/files/sitreps/473e6858195 3ff7e0d0b08445c1f6726.pdf

18. Otto JL, Holodniy M, DeFraites RF. Public health practice is not research. Am J Public Health. 2014;104:596-602.

19. Nikisins S, Rieger T, Patel P, Müller R, Günther S, Niedrig M. International external quality assessment study for molecular detection of Lassa virus. PLoS Negl Trop Dis. 2015;9:e0003793. http://dx.doi.org/10.1371/journal.pntd.0003793

20. Andersen KG, Shapiro BJ, Matranga CB, Sealfon R, Lin AE, Moses LM, et al.; Viral Hemorrhagic Fever Consortium. Clinical sequencing uncovers origins and evolution of Lassa virus. Cell. 2015;162:738-50. http://dx.doi.org/10.1016/j.cell.2015.07.020

21. Isere EE, Fatiregun AA, Ajayi IO. An overview of disease surveillance and notification system in Nigeria and the roles of clinicians in disease outbreak prevention and control. Niger Med J. 2015;56:161-8. http://dx.doi.org/10.4103/ 0300-1652.160347

22. National Bureau of Statistics. National population estimates [cited 2018 May 19] https://nigerianstat.gov.ng/download/474

23. Yalley-Ogunro JE, Frame JD, Hanson AP. Endemic Lassa fever in Liberia. VI. Village serological surveys for evidence of Lassa virus activity in Lofa County, Liberia. Trans R Soc Trop Med Hyg. 1984;78:764-70. http://dx.doi.org/10.1016/0035-9203(84)90013-0

24. Bausch DG, Demby AH, Coulibaly M, Kanu J, Goba A, Bah A, et al. Lassa fever in Guinea: I. Epidemiology of human disease and clinical observations. Vector Borne Zoonotic Dis. 2001;1:269-81. http://dx.doi.org/10.1089/15303660160025903

25. Fraser DW, Campbell CC, Monath TP, Goff PA, Gregg MB. Lassa fever in the Eastern province of Sierra Leone, 1970-1972. I. Epidemiologic studies. Am J Trop Med Hyg. 1974;23:1131-9. http://dx.doi.org/10.4269/ajtmh.1974.23.1131

26. Yinka-Ogunleye A, Ipadeola O, Saleh M, Ilori E, Dan-Nwafor C, Nwachukwu W, et al. 2016/2017 Lassa fever outbreak in Nigeria: age and sex have no effect on treatment outcome. Pan Afr Med J. 2018;8:3.

27. McCormick JB, King IJ, Webb PA, Johnson KM, O’Sullivan R, Smith ES, et al. A case-control study of the clinical diagnosis and course of Lassa fever. J Infect Dis. 1987;155:445-55. http://dx.doi.org/10.1093/infdis/155.3.445

28. Okokhere P, Colubri A, Azubike C, Iruolagbe C, Osazuwa O, Tabrizi S, et al. Clinical and laboratory predictors of Lassa fever outcome in a dedicated treatment facility in Nigeria: a retrospective, observational cohort study. Lancet Infect Dis. 2018; 18:684-95. http://dx.doi.org/10.1016/S1473-3099(18)30121-X

29. McCormick JB. Clinical, epidemiologic, and therapeutic aspects of Lassa fever. Med Microbiol Immunol (Berl). 1986;175:153-5. http://dx.doi.org/10.1007/BF02122438

30. Lo Iacono G, Cunningham AA, Fichet-Calvet E, Garry RF, Grant DS, Khan SH, et al. Using modelling to disentangle the relative contributions of zoonotic and anthroponotic transmission: the case of Lassa fever. PLoS Negl Trop Dis. 2015;9:e3398. http://dx.doi.org/10.1371/journal.pntd.0003398

31. Siddle KJ, Eromon P, Barnes KG, Mehta S, Oguzie JU, Odia I, et al. Genomic analysis of Lassa virus during an increase in cases in Nigeria in 2018. N Engl J Med. 2018;379:1745-53. http://dx.doi.org/10.1056/NEJMoa1804498

Address for correspondence: Chikwe Ihekweazu, Nigeria Centre for Disease Control, Plot 801 Ebitu Ukiwe, Jabi, Abuja, Nigeria; email: chikwe.ihekweazu@ncdc.gov.ng

\section{$\begin{array}{ll}.82 & \text { EMERGING } \\ \text { INFECTIOUS DISEASES }\end{array}$ \\ December 2018 \\ Zoonotic Infections}

- Outbreak of HIV Infection Linked to Nosocomial Transmission, China, 2016-2017

- Autochthonous Human Case of Seoul Virus Infection, the Netherlands

- Reemergence of St. Louis Encephalitis Virus in the Americas

- Restaurant Inspection Letter Grades and Salmonella Infections, New York City

- Spatial Analysis of Wildlife Tuberculosis Based on a Serologic Survey Using Dried Blood Spots, Portugal

- Comparison of Highly Pathogenic Avian Influenza H5 Guangdong Lineage Epizootic in Europe (2016-17) with Previous HPAI H5 Epizootics

- Capnocytophaga canimorsus Capsular Serovar and Disease Severity, Helsinki, Finland, 2000-2017

- Rat Lungworm Infection in Rodents Across Post-Katrina New Orleans, Louisiana

- Crimean-Congo Hemorrhagic Fever Virus, Mongolia, 2013-2014

- Emerging Multidrug-Resistant Hybrid Pathotype Shiga toxin-producing Escherichia coli $\mathrm{O} 80$ and Related Strains of Clonal Complex 165, Europe

- Terrestrial Bird Migration and West Nile Virus Circulation, United States

- Substance Use and Adherence to HIV Prexposure Prophylaxis for Men Who Have Sex with Men

- Genomic Characterization of $\beta$-Glucuronidase-Positive Escherichia coli 0157:H7 Producing Stx2a

- Highly Pathogenic Clone of Shiga Toxin-producing Escherichia coli 0157:H7, England and Wales

- CTX-M-65 Extended-Spectrum $\beta$-Lactamase-Producing Salmonella Serotype Infantis, United States

- Novel Type of Chronic Wasting Disease Detected in Moose (Alces alces), Norway

- Survey of Ebola Viruses in Frugivorous and Insectivorous Bats in Guinea, Cameroon, and the Democratic Republic of the Congo, 2015-2017

To revisit the December 2018 issue, go to:

https://wwwnc.cdc.gov/eid/articles/ issue/24/12/table-of-contents 